\title{
Mitigation of 21st century Antarctic sea ice loss by stratospheric ozone recovery
}

\author{
Karen L. Smith, ${ }^{1}$ Lorenzo M. Polvani, ${ }^{1,2}$ and Daniel R. Marsh ${ }^{3}$ \\ Received 28 July 2012; revised 11 September 2012; accepted 17 September 2012; published 16 October 2012.
}

[1] We investigate the effect of stratospheric ozone recovery on Antarctic sea ice in the next half-century, by comparing two ensembles of integrations of the Whole Atmosphere Community Climate Model, from 2001 to 2065 . One ensemble is performed by specifying all forcings as per the Representative Concentration Pathway 4.5; the second ensemble is identical in all respects, except for the surface concentrations of ozone depleting substances, which are held fixed at year 2000 levels, thus preventing stratospheric ozone recovery. Sea ice extent declines in both ensembles, as a consequence of increasing greenhouse gas concentrations. However, we find that sea ice loss is $\sim 33 \%$ greater for the ensemble in which stratospheric ozone recovery does not take place, and that this effect is statistically significant. Our results, which confirm a previous study dealing with ozone depletion, suggest that ozone recovery will substantially mitigate Antarctic sea ice loss in the coming decades. Citation: Smith, K. L., L. M. Polvani, and D. R. Marsh (2012), Mitigation of 21st century Antarctic sea ice loss by stratospheric ozone recovery, Geophys. Res. Lett., 39, L20701, doi:10.1029/2012GL053325.

\section{Introduction}

[2] While Arctic sea ice extent (SIE) has experienced a marked decline over the past several decades [Comiso et al., 2008], Antarctic SIE has exhibited a weak yet statistically significant positive trend of $0.97 \%$ per decade since the late 1970s [Comiso and Nishio, 2008; Stammerjohn et al., 2008; Turner et al., 2009]. This small positive trend, however, results from large regional cancellations, since the observed changes in Antarctic sea ice have been found to be highly non-zonal in character. Specifically, sea ice has advanced in the Weddell and Ross Sea, while it has declined in the Amundsen-Bellingshausen Seas [Yuan and Martinson, 2000; Zwally et al., 2002]. Whether these trends are a simple manifestation of unforced climate variability or the response to anthropogenic forcings remains unclear.

[3] Among anthropogenic forcings, stratospheric ozone depletion has received much recent attention. A number of

\footnotetext{
${ }^{1}$ Lamont-Doherty Earth Observatory, Earth Institute at Columbia University, Palisades, New York, USA.

${ }^{2}$ Department of Applied Physics and Applied Mathematics and Department of Earth and Environmental Sciences, Columbia University, New York, New York, USA.

${ }^{3}$ Atmospheric Chemistry Division, National Center for Atmospheric Research, Boulder, Colorado, USA.

Corresponding author: K. L. Smith, Lamont-Doherty Earth Observatory, Earth Institute at Columbia University, 301F Oceanography, 61 Rte. 9W, P.O. Box 1000, Palisades, NY 10964-8000, USA. (ksmith@ldeo.columbia.edu)

(C)2012. American Geophysical Union. All Rights Reserved. 0094-8276/12/2012GL053325
}

studies have demonstrated that ozone depletion over the South Pole has had a major impact on the atmospheric circulation in recent decades [see, e.g., Polvani et al., 2011a, and references therein]. Notably, polar ozone depletion is believed to have caused a substantial poleward shift of the midlatitude jet in the Southern Hemisphere ( $\mathrm{SH}$ ) summertime, which is often referred to as a positive trend in the Southern Annular Mode (SAM), as recently reviewed in Thompson et al. [2011]. The SAM, in turn, has been linked to SIE in a number of studies [Hall and Visbeck, 2002; Lefebvre et al., 2004; Sen Gupta and England, 2006; Stammerjohn et al., 2008; Goosse et al., 2009], at least on interannual time scales. And, most recently, Turner et al. [2009] have argued that the observed positive trend in autumn SIE in the Ross Sea is related to the contemporary positive trend in the SAM associated with stratospheric ozone depletion.

[4] In contrast, several other studies [Lefebvre et al., 2004; Liu et al., 2004] have suggested that, although the SAM might be correlated with SIE on interannual time scales, recent decadal trends in the SAM are unable to explain the observed SIE trends. Perhaps the strongest evidence for this is the recent work of Sigmond and Fyfe [2010] (hereinafter SF10). Using highly-controlled, single-forcing, time-slice model simulations, they show that Antarctic SIE in fact decreases in all regions when their model is forced with a prescribed ozone hole relative to a control run, particularly in summer and winter. From this, they argue that ozone depletion and the associated positive SAM trends cannot be responsible for the observed positive trends in Antarctic SIE which, therefore, are likely a manifestation of the internal variability of the climate system.

[5] In this paper we turn to the future, and document the effects of ozone recovery on Antarctic sea ice in the coming decades. To the best of our knowledge, ours is the first modeling study to specifically address this question. Using a fully coupled, state-of-the-art, stratosphere-resolving model with interactive stratospheric chemistry, we compare integrations with and without imposed trends in ozone depleting substances over the period 2001-2065, and we find that the expected recovery of stratospheric ozone will substantially mitigate the projected loss of sea ice in the coming half century.

\section{Methods}

[6] We employ Version 4 of the Whole Atmosphere Community Climate Model (WACCM4), the stratosphereresolving, coupled-chemistry version of the NCAR Community Climate Model Version 4 (CCSM4) [Gent et al., 2011]. The land, ocean and sea ice components of WACCM4 are identical to those in CCSM4. In contrast, the 
(a) OND Polar-Cap Averaged Total Column Ozone

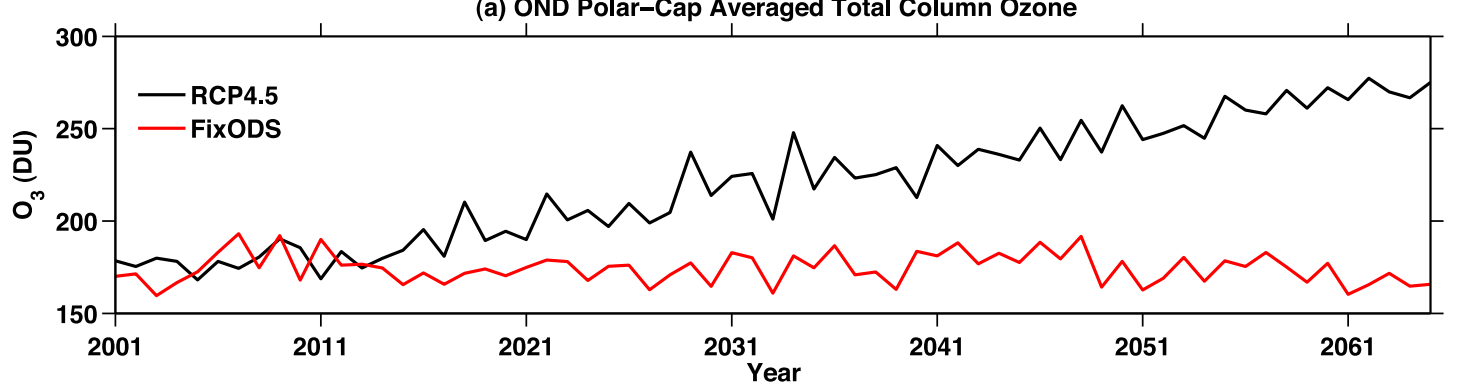

(b) JFM

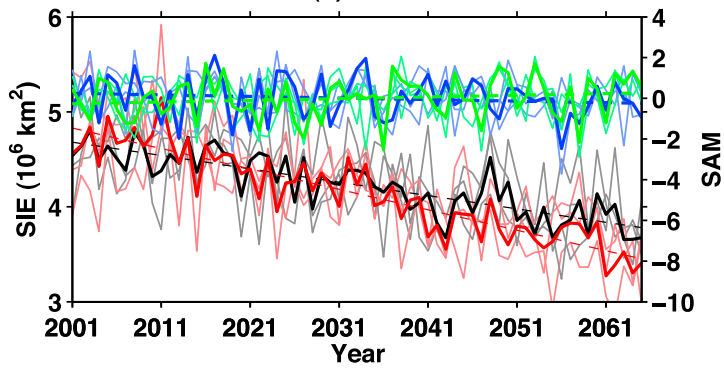

(d) JAS

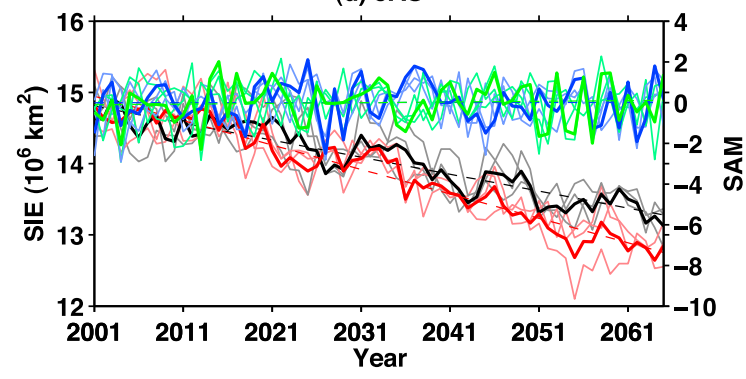

(c) AMJ

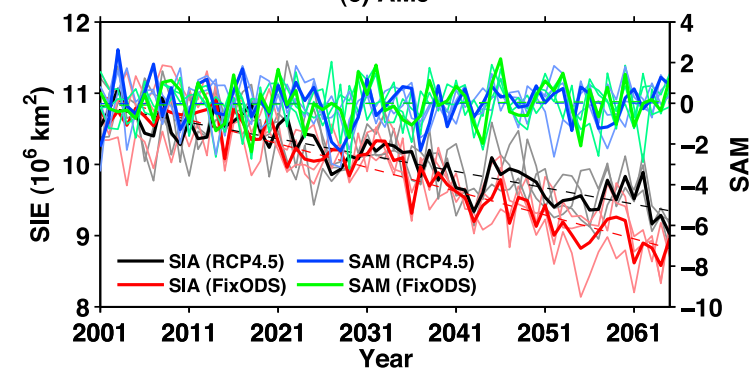

(e) OND

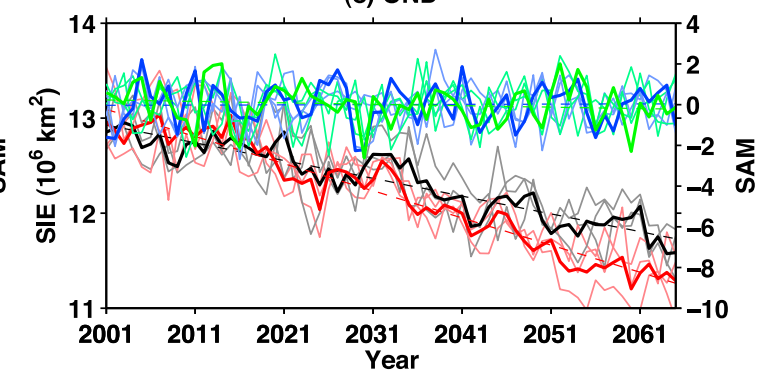

Figure 1. (a) October-November-December (OND) ensemble mean, polar-cap averaged, total column ozone (in Dobson Units) for the RCP4.5 (black) and FixODS (red) ensembles. Seasonal, ensemble mean time series of Antarctic sea ice area (SIA) and the Southern Annular Mode Index (SAM) for the RCP4.5 (thick black and blue curves, respectively) and the FixODS ensembles (thick red and green curves, respectively): (b) January-February-March (JFM), (c) April-May-June (AMJ), (d) July-August-September (JAS) and (e) October-November-December (OND). Individual ensemble members are shown by the thin curves with the same color scheme; dashed lines are least-squares linear fits to the ensemble mean curve.

atmospheric component of WACCM4 has 66 vertical levels with a model top at $140 \mathrm{~km}$, a horizontal resolution of $1.9^{\circ} \times$ $2.5^{\circ}$, special parameterizations for gravity waves and other upper atmospheric process and, most importantly, fullyinteractive stratospheric chemistry. For further details the reader is referred to D. R. Marsh et al. (Climate change from 1850-2005 simulated in CESM1 (WACCM), submitted to Journal of Climate, 2012).

[7] To unambiguously bring out the role of ozone recovery we contrast two ensembles of model runs, each comprised of 3 integrations, from 2001 to 2065 . For the first ensemble (labeled "RCP4.5") all forcings are specified following Representative Concentration Pathway 4.5 [Meinshausen et al., 2011]. The ensemble members are initialized from 3 corresponding historical integrations of the same model (Marsh et al., submitted manuscript, 2012). For the second ensemble (labeled "FixODS"), everything is identical except for the surface concentrations of ozone-depleting substances (ODS), which are held fixed at year 2000 levels. In other words, we compare two future scenarios in which greenhouse gas (GHG) concentrations increase, but one includes ozone recovery and the other does not. This is shown in Figure 1a, where we plot the ensemble mean, October-NovemberDecember (OND), total column ozone, averaged from 60$90^{\circ} \mathrm{S}$, for both ensembles. SH polar cap ozone recovers for the RCP4.5 case (black) but remains constant for the FixODS case (red).

[8] In what follows, the response to fixing ODS is documented by computing the ensemble-mean differences, between the FixODS and RCP4.5 cases, averaged over the final ten years of each integration (i.e. 2056-2065). We have also calculated the differences in the ensemble-mean 20012065 trends, and find that they are qualitatively similar to the 2056-2065 differences. Unless otherwise stated, we used the 95\% level to define statistical significance.

[9] We recall that SIE is calculated by summing the total area of all model grid cells for which sea ice concentration (SIC) exceeds $15 \%$, whereas sea ice area (SIA) is calculated by summing the fractional area of all model grid cells for which SIC exceeds $15 \%$. Both SIE and SIA will be used to show the impact of ozone recovery in our model. Finally, we note that the SAM index is here computed as the principal component time series of the first empirical orthogonal 

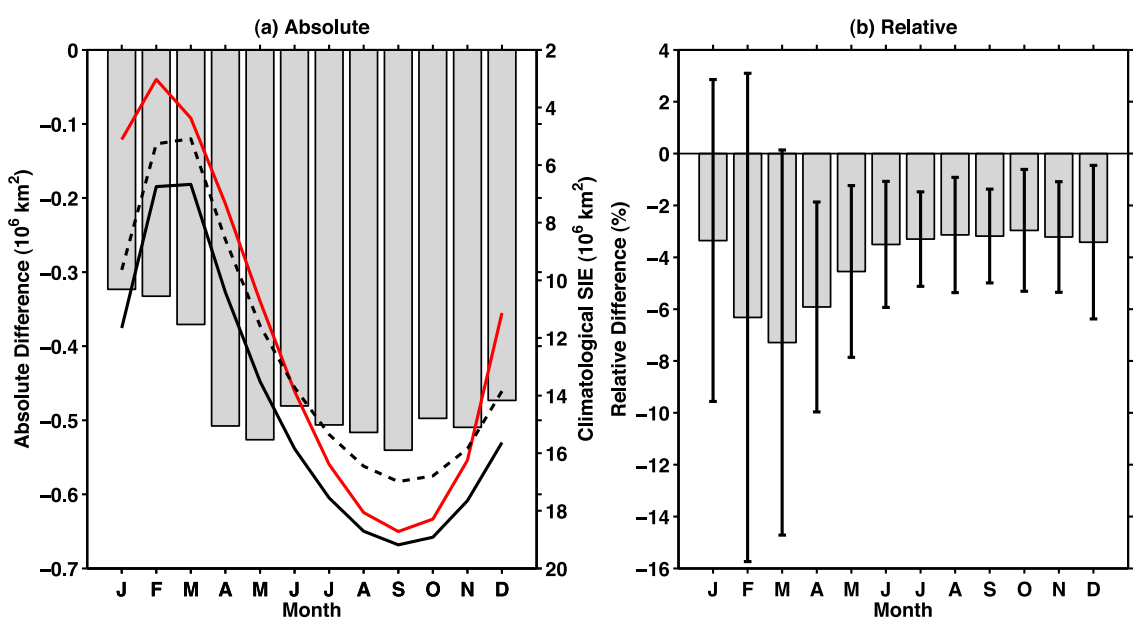

Figure 2. Seasonal cycle of the (a) absolute $\left(10^{6} \mathrm{~km}^{2}\right)$ and (b) relative (\%) response in Antarctic sea ice extent (SIE) to fixing ODS. Grey bars shown the monthly, ensemble mean FixODS-RCP4.5 differences, averaged over the period 20562065. In Figure 2a the WACCM4 climatological Antarctic SIE, averaged 1979-2005 in the historical period, is shown in the black solid line; the WACCM4 Antarctic SIE, averaged 2056-2065 in the RCP4.5 ensemble, is shown in the black dashed line; and the observed climatological Antarctic SIE from 1979-2010 is shown in the red line. 95\% confidence intervals are shown in Figure 2b.

function (EOF) of seasonally averaged monthly sea level pressure (SLP) anomalies from 20 to $90^{\circ} \mathrm{S}$.

\section{Results}

[10] The impact of ozone recovery on Antarctic sea ice area (SIA) is immediately seen by contrasting the red (FixODS) and black (RCP4.5) curves in Figures 1b-1e; the different panels show different seasons. In all cases SIA shows a statistically significant decline as a consequence of increasing GHGs. However, in the absence of ozone recovery (red curves) the decline in SIA is significantly greater: this is the key result of our paper.

[11] It is important to note that the impact of ozone recovery on SIA is present in all seasons, even though the atmospheric circulation changes accompanying stratospheric ozone trends are largely confined to the summer [Perlwitz et al., 2008; Son et al., 2009, 2010; Polvani et al., 2011a, 2011b]. As shown below, this is due to the ocean temperatures, which impart a longer memory to the seasonally confined ozone trends, and allow stratospheric ozone to impact sea ice throughout the entire year.

[12] The SAM index is also shown in Figures 1b-1e, for the RCP4.5 (blue) and FixODS (green) cases. Only in JFM we find a statistically significant difference in the SAM (at the $90 \%$ confidence level) between the FixODS and the RCP4.5 integrations: this is not surprising, as ozone recovery would act on the SAM in summer only. Although barely visible in Figure 1b, this difference will prove important, as described below. In the other seasons SAM trends have little to do with SIA trends.

[13] We also note that all SAM trends are very small in these integrations. The absence of SAM trends in JFM is likely a result of the cancellation between increasing GHGs and ozone recovery [Arblaster et al., 2011; Polvani et al., $2011 \mathrm{~b}]$. For the other seasons, the increase in GHG concentrations to 2065 with the RCP4.5 forcings might not be sufficiently large for a statistically significant SAM to emerge from the very large internal variability [Deser et al.,
2012]. As a point of comparison, we note that very little, significant, zonal mean, zonal wind trends have been documented in the CMIP5 multi-model mean over the period 2000-2050, even for the stronger RCP 8.5 forcings [see Wilcox et al., 2012, Figure 8d].

[14] To verify that our results are robust across different metrics of sea ice, we have also examined the impact of ozone recovery on sea ice extent (SIE) in our model. This is summarized in Figure 2, where we plot the absolute (panel a) and relative (panel b) ensemble-mean response in SIE to fixing ODS, averaged over the decade 2056-2065. The negative gray bars indicate that the FixODS integrations yield larger sea ice loss than the RCP4.5 ones. The confidence intervals in panel (b) indicate that the response is statistically significant in all months except January, February and March when the variability in sea ice extent is the largest. For reference, we also plot in Figure 2a the climatological seasonal cycle of Antarctic sea ice in WACCM for the historical period, averaged 1979-2005 (solid black curve), and the corresponding satellite observations over the same period (red curve) from Fetterer et al. [2002] (updated 2009). Contrasting these two curves, one sees that the seasonal cycle of Antarctic sea ice in WACCM4 is in fairly good agreement with observations in winter and early spring, but too extensive for the rest of the year. This differs considerably from the CCSM4 seasonal cycle [Landrum et al., 2012], which is more extensive than the observations in all seasons.

[15] Note that the mitigating impact of stratospheric ozone recovery is very robust, as all months show a larger SIE loss when ozone recovery is absent (FixODS). The largest absolute response (Figure 2a) occurs in fall, winter and spring, when climatological sea ice is most extensive. Instead, the largest relative response (Figure $2 b$ ) occurs in summer, when climatological sea ice is at its minimum, but when ozone induced surface anomalies are largest, as described below. We also find that the negative response in SIE is accompanied by a decrease in ice thickness in all months (not shown). We wish to stress that these results, 

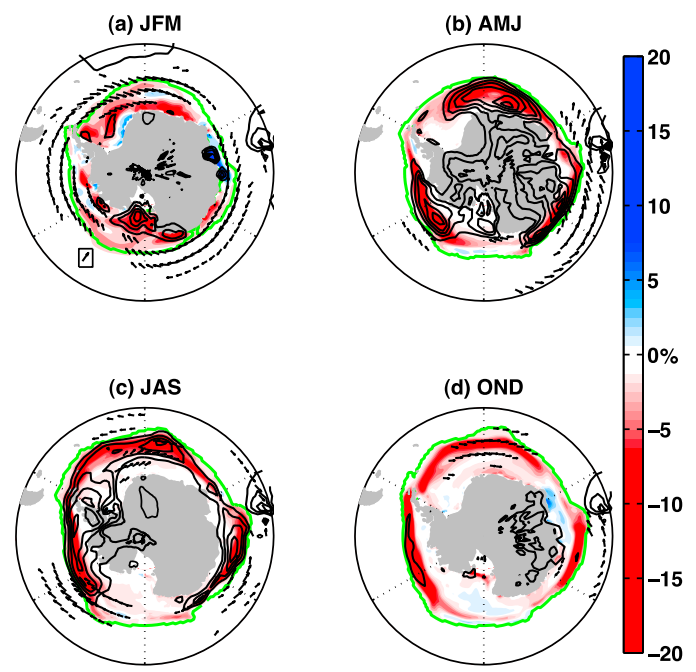

Figure 3. Seasonal response in sea ice concentration (\%; shading), surface wind stress (black vectors; only vectors greater than $0.01 \mathrm{~N} \mathrm{~m}^{2}$ are displayed), surface temperature (black curves; solid and dashed correspond to positive and negative values; contour interval in $\mathrm{K}$ is $[\ldots,-1.25,-1$, $-0.75,-0.5,0,0.5,0.75,1,1.25, \ldots])$. (a) JFM, (b) AMJ, (c) JAS and (d) OND. Inset in Figure 3a shows a vector of length $0.02 \mathrm{~N} \mathrm{~m}^{2}$.

including the seasonal dependency of the absolute and relative responses, are in fundamental agreement with those reported in SF10 who found, using a quite different model and looking at the past, that ozone depletion increases sea ice loss.

[16] In Figure 2a we also plot the seasonal cycle of SIE averaged 2056-2065 for the RCP4.5 ensemble (dashed black curve). The separation between the solid and dashed black lines, therefore, shows the magnitude of the modeled SIE loss due climate change from all forcings in the coming half century (scale to the right). This magnitude can now be contrasted with the magnitude associated with ozone recovery (grey bars, scale to the left): our results indicate that, in our model, ozone recovery prevents approximately $33 \%$ of the annual mean Antarctic sea ice loss projected to occur in the coming decades.

[17] At this point the obvious question is: what causes the stronger sea ice loss in the absence of ozone recovery? As in SF10, the answer comes in two parts. First, we describe the impact of ozone recovery on surface winds and the ocean circulation in the summer, where the largest relative SIE response is found (Figure 2b). Second, we show how this impact carries over to the other seasons, yielding largest absolute SIE responses then (Figure 2a).

[18] Let us then consider the SIC response in JFM, shown in colors in Figure 3a: it is clear that, when ODS are held fixed, SIC decreases almost everywhere around Antarctica, except for small regions in the Indian Ocean sector. The ice edge, averaged over the last ten years of the RCP4.5 ensemble, is indicated in green by the $15 \%$ SIC contour. The black contours show surface temperature response, and we note that it increases/decreases in the regions of greatest sea ice loss/growth.

[19] More important, however, is the response in the zonal wind stress, shown by the black arrows in Figure 3a. The enhanced zonal wind stress is due to the strong influence of spring ozone depletion on the summer SAM, which is more positive in the FixODS integrations. Accompanying the increased wind stresses we find a deeper mixed layer in all sectors (not shown). Such coherent annular patterns in wind stress and mixed layer depth are typical of positive phases of the SAM [Hall and Visbeck, 2002; Sen Gupta and England, 2006] which, in our model, must originate from the difference in stratospheric ozone, as that is the only altered forcing between the two ensembles of integrations.

[20] Associated with the strengthening of the zonal wind stress in JFM we find an increase in equatorward Ekman drift, illustrated in Figure $4 \mathrm{a}$ by an enhancement in the (a) JFM

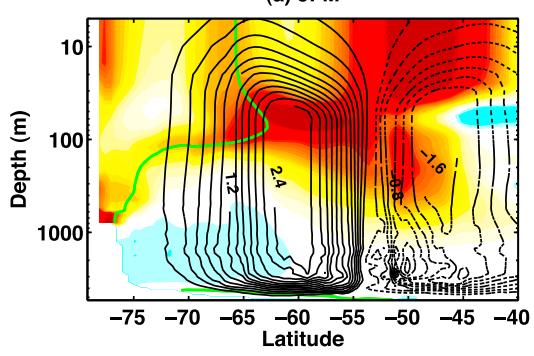

(c) JAS

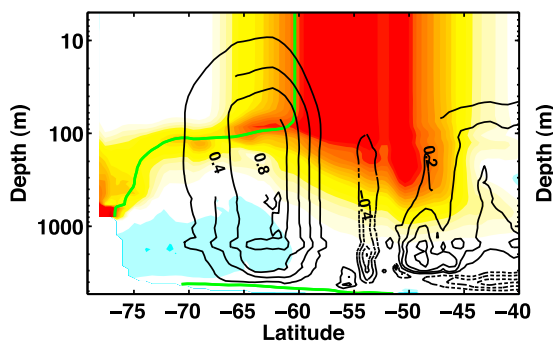

(b) AMJ

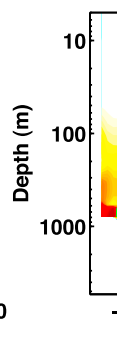

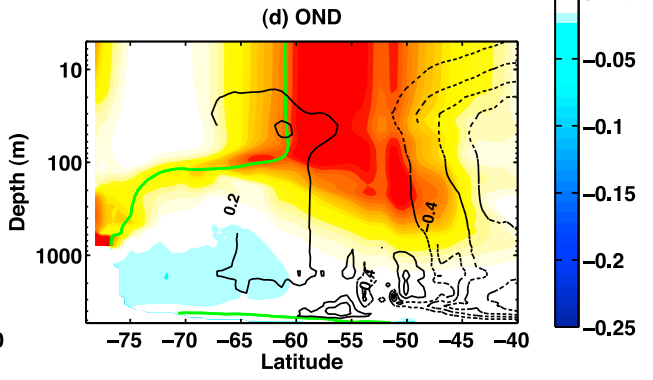

Figure 4. Seasonal response in zonal mean ocean temperature $\left({ }^{\circ} \mathrm{C}\right.$; shading) and meridional overturning circulation (black curves; solid and dashed correspond to positive and negative values; contour interval is 0.2 Sv). (a) JFM, (b) AMJ, (c) JAS and (d) OND. 
surface branch of the meridional overturning circulation (MOC) at $\sim 65^{\circ} \mathrm{S}$, near the ice edge (approximated by the $0^{\circ} \mathrm{C}$ contour, in green). The equatorward flow upwells warm waters from below, and also carries cold surface waters equatorward leading to a local minimum in upper ocean temperature difference near $60^{\circ} \mathrm{S}$ (yellow region in Figure $4 \mathrm{a})$. Despite these competing effects, the upper ocean temperature response at $60^{\circ} \mathrm{S}$ is positive due in part to a deepening of the mixed layer (not shown) indicated by the warming at $\sim 70 \mathrm{~m}$ depth (see also Figure 4 of SF10). At $\sim 55^{\circ} \mathrm{S}$ one sees convergence and downwelling, which brings warm equatorial waters poleward creating a maximum temperature anomaly in the upper ocean near $50^{\circ} \mathrm{S}$.

[21] In summary then, the net effect of the stronger summertime positive SAM anomalies in the FixODS ensemble is to enhance sea ice export near the ice edge due to a larger equatorward Ekman drift, and restrict equatorward growth due to upper ocean warming near the ice edge. We emphasize that these impacts, caused by atmospheric circulation changes, were previously reported by SF10 for the case of ozone depletion, and we are here confirming them, with a different model, for the case of ozone recovery.

[22] Having documented the summer changes in atmosphere and ocean circulation, and their effect of ocean temperatures and SIC, we now turn to the largest absolute response in SIE which occurs in the other seasons. As seen in Figures $3 b-3 d$, large negative SIC responses accompany lack of ozone recovery, and a corresponding increase in surface temperature is seen in the regions of greatest ice loss: the Weddell Sea, the Amundsen-Bellingshausen Seas and the Western Pacific Ocean. As noted in SF10, the SIC response in these seasons occurs away from the Antarctic continent, see Figures $3 \mathrm{~b}-3 \mathrm{~d}$, in contrast to the summer response which occurs near the continent (Figure $3 \mathrm{a}$ ).

[23] Also in agreement with SF10, we find that the decrease in SIE for the FixODS ensemble is related to a warming of the upper ocean, as shown in Figures $4 b-4 d$. The ocean temperature acts as a thermodynamic constraint on the equatorward extent of sea ice growth: the ocean warming pushes the ice edge poleward, while also reducing the thickness of the ice (not shown). This ocean warming is attributed to the changes in the meridional overturning circulation occurring in summer, when the SAM anomaly, i.e. the poleward intensification of the westerly jet, is strongest: it persists into the fall, winter and spring due to the slower timescales in the ocean. In fact, that the ocean warming is not connected to anomalies in mixed layer depth in fall, winter or spring (not shown), as the anomalous zonal wind stress is restricted to the summer season, as seen in Figures $3 b-3 d$.

\section{Summary and Discussion}

[24] With transient integrations using a state-of-the-art, stratosphere resolving, coupled-chemistry model, with land, ocean and sea ice components, we have shown that the projected recovery of stratospheric ozone will act to mitigate the loss of Antarctic sea ice expected to occur due to increasing GHG in the coming half century. The primary cause of the smaller loss of sea ice when ozone recovery is present is the effect of the reduced summertime wind stress

\footnotetext{
${ }^{1}$ Auxiliary materials are available in the HTML. doi:10.1029/ 2012 GL053325.
}

on the upper ocean at high-latitudes, which produces cooler ocean temperatures that persist in all seasons, and allow for a larger SIE than would occur in the absence of ozone recovery.

[25] Our findings are in complete agreement with those reported by SF10, who found ozone depletion to cause a decrease in SIE. Even the mechanisms we have documented in our model were found to be very similar to those detailed in SF10. Given that the models, the forcings and the time periods are quite distinct between these two studies, such good agreement is strong evidence for the robustness of these results. Furthermore, another more recent study, using an eddy-resolving ocean model, shows a similar Antarctic sea ice response to stratospheric ozone perturbations [Bitz and Polvani, 2012]. Hence, the response documented here appears to be robust to ocean model resolution.

[26] Also, consistent with earlier studies [SF10; Sen Gupta and England, 2006], we find a statistically significant positive correlation $(\sim 0.5)$ between the detrended autumn SIE and the summer SAM in each member of our ensembles (Figure S1a in the auxiliary material). ${ }^{1}$ However, when computed with trends retained these correlations weaken considerably (Figure S1b). Thus, the interannual relationship between Antarctic SIE and the SAM does not carry over to longer time scales. As we have shown, the modeling evidence is that ocean temperatures affect SIE on longer time scales, not the SAM.

[27] Finally, to broaden the scope of our study, we note that our findings provide novel, substantial evidence that the regulation of chlorofluorocarbons by the Montreal Protocol will have climate implications well beyond the reduction of harmful ultra-violet radiation on biological organisms at high latitudes. The closing of the ozone hole, expected to occur in the next several decades, will have profound influences on many aspects of the $\mathrm{SH}$ climate system: the mitigation of sea ice loss is simply one more item which had not, to date, been documented.

[28] Acknowledgments. This work was funded, in part, by a grant from the US National Science Foundation (NSF) to Columbia University. All model integrations were performed at the National Center of Atmospheric Research (NCAR), which is sponsored by the US NSF. We would like to thank Mike Mills and Doug Kinnison, at NCAR, for their assistance with the model integrations. L.M.P. is particularly grateful to Marilyn Raphael and Cecilia Bitz for illuminating conversations and thoughtful comments on early drafts of this manuscript.

[29] The Editor thanks two anonymous reviewers for their assistance in evaluating this paper.

\section{References}

Arblaster, J. M., G. A. Meehl, and D. J. Karoly (2011), Future climate change in the Southern Hemisphere: Competing effects of ozone and greenhouse gases, Geophys. Res. Lett., 38, L02701, doi:10.1029/ 2010 GL045384.

Bitz, C. M., and L. M. Polvani (2012), Antarctic climate response to ozone depletion in a fine resolution ocean climate model, Geophys. Res. Lett., doi:10.1029/2012GL053393, in press.

Comiso, J. C., and F. Nishio (2008), Trends in the sea ice cover using enhanced and compatible AMSR-E, SSM/I, and SMMR data, J. Geophys. Res., 113, C02S07, 22, doi:10.1029/2007JC004257.

Comiso, J. C., C. L. Parkinson, R. Gersten, and L. Stock (2008), Accelerated decline in the Arctic sea-ice cover, Geophys. Res. Lett., 35 , L01703, doi:10.1029/2007GL031972.

Deser, C., A. Phillips, V. Bourdette, and H. Teng (2012), Uncertainty in climate change projections: The role of internal variability, Clim. Dyn., 38, 527-546, doi:10.1007/s00382-010-0977-x.

Fetterer, F., K. Knowles, W. Meier, and M. Savoie (2002), Sea Ice Index, http://nsidc.org/data/g02135.html, Natl. Snow and Ice Data Cent., Boulder, Colo. 
Gent, P. R., et al. (2011), The Community Climate System Model version 4, J. Clim., 24, 4973-4991, doi:10.1175/2011JCLI4083.1.

Goosse, H., W. Lefebvre, A. de Montety, E. Crespin, and A. H. Orsi (2009), Consistent past half-century trends in the atmosphere, the sea ice and the ocean at high southern latitudes, Clim. Dyn., 33(7-8), 999-1016, doi:10.1007/s00382-008-0500-9.

Hall, A., and M. Visbeck (2002), Synchronous variability in the Southern Hemisphere atmosphere, sea ice, and ocean resulting from the annular mode, J. Clim., 15, 3043-3057.

Landrum, L., M. M. Holland, D. P. Schneider, and E. Hunke (2012), Antarctic sea ice climatology, variability and late twentieth-century change in CCSM4, J. Clim., 25, 4817-4838, doi:10.1175/JCLI-D-11-00289.1.

Lefebvre, W., H. Goosse, R. Timmermann, and T. Fichefet (2004), Influence of the Southern Annular Mode on the sea ice-ocean system, J. Geophys. Res., 109, C09005, doi:10.1029/2004JC002403.

Liu, J., J. A. Curry, and D. G. Martinson (2004), Interpretation of recent Antarctic sea ice variability, Geophys. Res. Lett., 31, L02205, doi:10.1029/2003GL018732.

Meinshausen, M., et al. (2011), The RCP greenhouse gas concentrations and their extensions from 1765 to 2300, Clim. Change, 109, 213-241.

Perlwitz, J., S. Pawson, R. L. Fogt, J. E. Nielson, and W. D. Neff (2008), Impact of stratospheric ozone hole recovery on Antarctic climate, Geophys. Res. Lett., 35, L08714, doi:10.1029/2008GL033317.

Polvani, L. M., D. W. Waugh, G. J. P. Correa, and S.-W. Son (2011a), Stratospheric ozone depletion: The main driver of 20th century atmospheric circulation changes in the Southern Hemisphere, J. Clim., 24 795-812, doi:10.1175/2010JCLI3772.1.

Polvani, L. M., M. Previdi, and C. Deser (2011b), Large cancellation, due to ozone recovery, of future Southern Hemisphere atmospheric circulation trends, Geophys. Res. Lett., 38, L04707, doi:10.1029/2011GL046712.

Sen Gupta, A., and M. H. England (2006), Coupled ocean-atmosphere-ice response to variations in the Southern Annular Mode, J. Clim., 19(18), 4457-4486, doi:10.1175/JCLI3843.1.
Sigmond, M., and J. C. Fyfe (2010), Has the ozone hole contributed to increased Antarctic sea ice?, Geophys. Res. Lett., 37, L18502, doi:10.1029/2010GL044301.

Son, S.-W., N. F. Tandon, L. M. Polvani, and D. W. Waugh (2009), Ozone hole and Southern Hemisphere climate change, Geophys. Res. Lett., 36 , L15705, doi:10.1029/2009GL038671.

S.-W. Son, et al. (2010), Impact of stratospheric ozone on Southern Hemisphere circulation change: A multimodel assessment, J. Geophys. Res., 115, D00M07, doi:10.1029/2010JD014271.

Stammerjohn, S. E., D. G. Martinson, R. C. Smith, X. Yuan, and D. Rind (2008), Trends in Antarctic annual sea ice retreat and advance and their relation to El Niño-Southern Oscillation and Southern Annular Mode variability, J. Geophys. Res., 113, C03S90, doi:10.1029/2007JC004269.

Thompson, D. W. J., S. Solomon, P. J. Kushner, M. H. England, K. M. Grise, and D. J. Karoly (2011), Signatures of the Antarctic ozone hole in Southern Hemisphere surface climate change, Nat. Geosci., 4, 741-749, doi:10.1038/ngeo1296.

Turner, J., J. C. Comiso, G. J. Marshall, T. A. Lachlan-Cope, T. Bracegirdle, T. Maksym, M. P. Meredith, Z. Wang, and A. Orr (2009), Non-annular atmospheric circulation change induced by stratospheric ozone depletion and its role in the recent increase of Antarctic sea ice extent, Geophys. Res. Lett., 36, L08502, doi:10.1029/2009GL037524.

Wilcox, L., A. J. Charlton-Perez, and L. J. Gray (2012), Trends in austral jet position in ensembles of high- and low-top CMIP5 models, J. Geophys. Res., 117, D13115, doi:10.1029/2012JD017597.

Yuan, X. J., and D. G. Martinson (2000), Antarctic sea ice extent variability and its global connectivity, J. Clim., 13(10), 1697-1717, doi:10.1175/ 1520-0442(2000)013<1697:ASIEVA>2.0.CO;2.

Zwally, H. J., J. C. Comiso, C. L. Parkinson, D. J. Cavalieri, and P. Gloersen (2002), Variability of Antarctic sea ice 1979-1998, J. Geophys. Res., 107(C5), 3041, doi:10.1029/2000JC000733. 